\title{
Microstructure and Mechanical Properties of Severely Deformed AX41 Magnesium Alloy
}

\author{
T. KrajŇÁK ${ }^{a, *}$, K. MÁthis $^{a}$, J. GubiczA ${ }^{b}$, J. StrásKÁ ${ }^{a}$ AND M. JANEČEK ${ }^{a}$ \\ ${ }^{a}$ Department of Physics of Materials, Faculty of Mathematics and Physics, Charles University, \\ Ke Karlovu 5, 12116 Prague 2, Czech Republic \\ ${ }^{b}$ Department of Materials Physics, Eötvös Loránd University, Budapest, Hungary
}

\begin{abstract}
The object of the present paper is the study of mechanical properties and microstructural evolution of AX41 magnesium alloy, severely deformed using a combination of hot extrusion and equal channel angular pressing. Equal channel angular pressing processing was performed at $250{ }^{\circ} \mathrm{C}$ following route Bc. Mechanical properties of the ultrafine-grained alloy were investigated in tension at a constant strain rate of $10^{-4} \mathrm{~s}^{-1}$ at room temperature and $100{ }^{\circ} \mathrm{C}$. The dislocation density was determined by X-ray line profiles analysis. Microstructural observations performed by electron backscattering diffraction after 8 passes of equal channel angular pressing revealed very fine and homogeneous microstructure with a grain size of $0.3-6 \mu \mathrm{m}$. It has been found that the room temperature mechanical properties such as yield stress and tensile strength reach their maximum value even after the first pass which is in good agreement with the evolution of the dislocation density. Further processing by equal channel angular pressing led to the decrease in both the yield strength and the dislocation density, despite the slight grain size refinement.
\end{abstract}

DOI: $10.12693 /$ APhysPolA.128.768

PACS: 81.40.-z, 61.05.cp, 68.37.Hk, 61.72.Lk, 61.72.Mm

\section{Introduction}

Magnesium and its alloys possess very high specific strength and it makes them very promising candidates for a wide range of structural applications for instance in electronics, transport and sport industry. Nevertheless, the applications of $\mathrm{Mg}$ alloys are still limited because of the low strength and formability, originating from the hexagonal close packed structure of magnesium.

In the last decade many attempts were done for improving the forming capability and mechanical properties of magnesium alloys. Processing by methods of severe plastic deformation (SPD), resulting in grain size reduction and introduction of large amount of lattice defects, was proven to be very effective for these purposes. Equal channel angular pressing (ECAP) $[1,2]$ is the most popular SPD technique, owing to its capability to produce large scale samples. To this date, a considerable number of magnesium alloys was processed using this method successfully [3-5]. Generally, ECAP processed Mg alloys exhibit increased values of yield strengths and ductility as well $[6,7]$.

In order to extend the current use of magnesium alloys from room temperature to high temperature applications, new ternary magnesium alloy of $\mathrm{AX}(\mathrm{Mg}-\mathrm{Al}-\mathrm{Ca})$ series was developed. This type of alloy possesses improved high temperature strength and creep resistance at $150^{\circ} \mathrm{C}$ comparable to the alloy $\mathrm{AE} 42$, thanks to the $\mathrm{Mg}_{2} \mathrm{Ca}$ and the $\mathrm{Al}_{2} \mathrm{Ca}$ Laves phases, present in the

*corresponding author; e-mail: tom.krajnak@gmail.com microstructure [8-10]. Cheaper and lighter Ca addition in contrast to the expensive rare-earth alloying elements makes AX magnesium alloys very promising candidates for commercial applications.

The main aim of the present work is to investigate the influence of ECAP processing on the mechanical properties and the microstructure of extruded AX41 magnesium alloy.

\section{Experimental material and procedures}

A commercial AX41 magnesium alloy $(\mathrm{Mg}-4 \mathrm{wt} \% \mathrm{Al}$ $1 \mathrm{wt} \% \mathrm{Ca}$ ) was first extruded at $350{ }^{\circ} \mathrm{C}$ at a speed of $60 \mathrm{~mm} / \mathrm{min}$ with an extrusion ratio (ER) of 19:1. After extrusion, ECAP via route $\mathrm{Bc}$ was performed at $250{ }^{\circ} \mathrm{C}$ up to a total of eight passes. Billets with dimensions of $10 \times 10 \times 100 \mathrm{~mm}^{3}$ were machined from the extruded rod and pressed with a speed of $20 \mathrm{~mm} / \mathrm{min}$ through a die consisting of rectangular channel (inner angle $\varphi=90^{\circ}$, outer curvature $\psi=0^{\circ}$ ) having a crosssection of $10 \times 10 \mathrm{~mm}^{2}$. For simplicity the samples were labeled according to the number of the applied ECAP passes. For instance the specimen processed by 2 passes is labeled as $2 \times \mathrm{Bc}$.

The study of the microstructure with increasing number of EX-ECAP passes was performed by optical microscopy as well as X-ray and electron diffraction techniques. Samples for microstructural investigations were cut from the rod perpendicular and parallel to the pressing direction, grinded by $1200,2000,4000$-grit $\mathrm{SiC}$ papers and subsequently polished by diamond suspensions with particle sizes of $1 \mu \mathrm{m}$ and $\frac{1}{4} \mu \mathrm{m}$. For final surface treatment the samples were etched by a solution of $10 \mathrm{ml}$ acetic acid, $4.2 \mathrm{~g}$ picric acid, $10 \mathrm{ml} \mathrm{H}_{2} \mathrm{O}$ and $70 \mathrm{ml}$ of 
ethanol for $10 \mathrm{~s}$. Before electron backscatter diffraction (EBSD) measurements, ion-polishing of samples was performed by a Gatan PIPS ${ }^{\top M}$ ion mill at $2 \mathrm{kV}$ and an incidence angle of $4^{\circ}$. EBSD investigations were taken using Quanta FEG scanning electron microscope operating at $10 \mathrm{kV}$ from the middle part of the billet.

Flat tensile specimens with rectangular cross-section of $6 \mathrm{~mm} \times 1 \mathrm{~mm}$ and gauge length of $13 \mathrm{~mm}$ were used for mechanical testing. Tensile tests were performed in a universal Instron 5882 testing machine at room temperature and $100^{\circ} \mathrm{C}$ with a constant cross head speed of $10^{-4} \mathrm{~s}^{-1}$.

The X-ray diffraction pattern was measured by a highresolution rotating anode diffractometer using $\mathrm{Cu} K_{\alpha_{1}}$ (wavelength: $\lambda=0.15406 \mathrm{~nm}$ ) radiation. The size of the $\mathrm{X}$-ray beam spot was set to about $2 \times 0.2 \mathrm{~mm}^{2}$. The X-ray diffraction patterns were evaluated by the convolutional multiple whole profile (CMWP) fitting method [11, 12]. Nineteen peaks of $\mathrm{Mg}$ were used in the fitting procedure, which correspond to an angular range of diffraction of about $30-135^{\circ}$. In this procedure, the diffraction pattern is fitted by the sum of a background spline and the convolution of the instrumental pattern and the theoretical line profiles related to the crystallite size and dislocations. The CMWP method gives the following parameters of the microstructure: the median of the crystallite size distribution $(m)$, the square root of the lognormal variance of the crystallite size distribution $(\sigma)$ and the dislocation density. The area-weighted mean crystallite size was calculated from the median and the lognormal variance as $\langle x\rangle_{\text {area }}=m \exp \left(2.5 \sigma^{2}\right)$.

\section{Experimental results and discussion}

The microstructure of the extruded AX41 alloy consists of magnesium matrix and eutectic $\mathrm{Al}_{2} \mathrm{Ca}$ Laves phase. This phase contributes to a considerable increase of hardness and yield strength of the material [8]. In the extruded material the grain structure has a bimodal character and new equiaxed grains can be observed, originating from dynamic recrystallization. Although the average grain size is $3.8 \mu \mathrm{m}$, a large number of grains with size between 10 and $20 \mu \mathrm{m}$ is present [13]. As a consequence of extrusion, the $\mathrm{Al}_{2} \mathrm{Ca}$ phase is directionally aligned, parallel to the pressing direction, whereas in the as-cast state, this phase segregated at grain boundaries [14].

The microstructures after one and two EX-ECAP passes are depicted in Fig. 1a and b, respectively. After one pass (Fig. 1a), the onset of grain fragmentation process can be observed, namely nucleation of fine grains along the preexisting grain boundaries (some of them are indicated by arrows). The coarse grains having serrated grain boundaries are surrounded by arrays of much smaller grains. Such a process is in accordance with dynamic recrystallization models worked out for magnesium alloys [15, 16]. Deformation twins can also be observed, preferentially in the coarse grains. After two passes, the grain fragmentation occurs in the entire volume (see Fig. 1b). Prevailing part of the microstructure

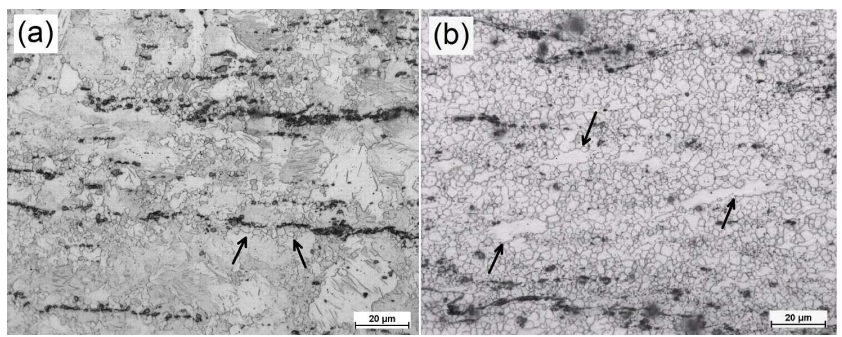

Fig. 1. Optical micrographs on the longitudinal section of (a) $1 \times \mathrm{Bc}$ and (b) $2 \times \mathrm{Bc}$ samples.

contains very fine new grains. Nevertheless, coarse grains (indicated by arrows) are still present.

Because of the limited resolution of the optical microscope, the microstructures of the samples after four and eight passes were investigated in detail by EBSD, as shown in Fig. 2. ECAP processing up to four passes does not lead to complete refinement of the microstructure, because of the ongoing process of grain growth (Fig. 2a). The grains in the vicinity of the particles $\mathrm{Al}_{2} \mathrm{Ca}$ (black colored) remained unchanged, due to the pinning effect of the $\mathrm{Al}_{2} \mathrm{Ca}$ phase on the grain boundaries. It should also be noted that during ECAP, the $\mathrm{Mg}_{17} \mathrm{Al}_{12}$ phase also formed besides $\mathrm{Al}_{2} \mathrm{Ca}$, as revealed by X-ray diffraction. The average grain size determined by the linear intercept method is $1.7 \mu \mathrm{m}$. Only the grains separated by high angle grain boundaries were taken into account. After eight passes (Fig. 2b) a homogeneous microstructure is formed having equiaxed grains with an average grain size of $1.5 \mu \mathrm{m}$. It is noteworthy that there is a significant difference between the fraction of high angle grain boundaries in $4 \times \mathrm{B}_{c}$ and $8 \times \mathrm{B}_{c}$ samples. Whereas the fraction of high angle grain boundaries for $4 \times \mathrm{B}_{c}$ sample is $86 \%$, in the case of $8 \times \mathrm{B}_{c}$ specimen this fraction decreases to $55 \%$, which is similar to the value observed for the initial, extruded sample $(61 \%)$.

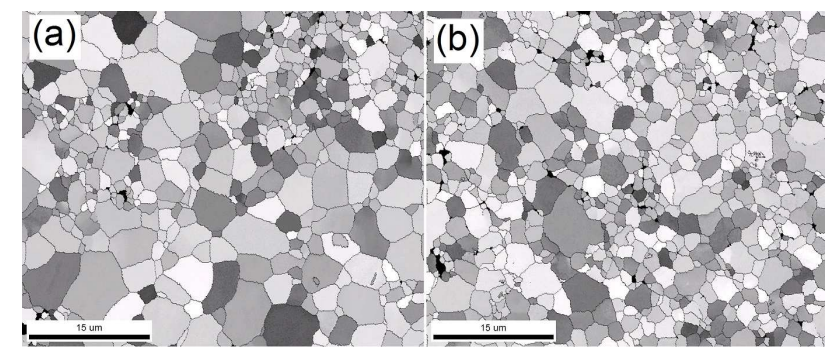

Fig. 2. Inverse pole figures obtained on the cross section of (a) $4 \times \mathrm{Bc}$ and (b) $8 \times \mathrm{Bc}$ samples.

The dislocation density and the crystallite size $\left(\langle x\rangle_{\text {area }}\right)$ in EX-ECAP samples measured by X-ray line profile analysis are summarized in the Table. During the first pass of ECAP the dislocation density considerably increases. However, after the first pass the dislocation density decreases with increase of number of 
TABLE

Parameters of the microstructure and the plastic behavior obtained by X-ray line profile analysis, EBSD and tensile tests: the area-weighted mean crystallite size $\left(\langle x\rangle_{\text {area }}\right)$, the dislocation density $(\rho)$, the grain size $(d)$, the fraction of high-angle grain boundaries $\left(f_{\mathrm{HAB}}\right)$, the yield strength at room temperature $\left(\sigma_{02}^{\mathrm{RT}}\right)$ and $100^{\circ} \mathrm{C}\left(\sigma_{02}^{100^{\circ} \mathrm{C}}\right)$.

\begin{tabular}{c|c|c|c|c|c|c}
\hline \hline $\begin{array}{c}\text { Number of } \\
\text { EX-ECAP }\end{array}$ & \multicolumn{2}{|c|}{ X-ray } & \multicolumn{2}{c|}{ EBSD } & \multicolumn{2}{c}{ Tensile tests } \\
\cline { 2 - 7 } passes & $\begin{array}{c}\langle x\rangle_{\text {area }} \\
{[\mathrm{nm}]}\end{array}$ & $\begin{array}{c}\rho \\
{\left[10^{14} \mathrm{~m}^{-2}\right]}\end{array}$ & $\begin{array}{c}d \\
{[\mu \mathrm{m}]}\end{array}$ & $\begin{array}{c}f_{\mathrm{HAB}} \\
{[\%]}\end{array}$ & $\begin{array}{c}\sigma_{02}^{\mathrm{RT}} \\
{[\mathrm{MPa}]}\end{array}$ & $\begin{array}{c}\sigma_{02}^{100^{\circ} \mathrm{C}}[\mathrm{MPa}] \\
{[\mathrm{MPa}]}\end{array}$ \\
\hline Extruded & $1 \mu \mathrm{m}<$ & $<0.1$ & $3.8 \pm 0.4$ & 61 & 159 & 134 \\
\hline $1 \times \mathrm{Bc}$ & $219 \pm 22$ & $0.9 \pm 0.1$ & - & - & 178 & 143 \\
\hline $2 \times \mathrm{Bc}$ & $277 \pm 28$ & $0.8 \pm 0.1$ & - & - & 158 & 133 \\
\hline $4 \times \mathrm{Bc}$ & $498 \pm 50$ & $0.4 \pm 0.1$ & $1.7 \pm 0.2$ & 86 & 117 & 106 \\
\hline $8 \times \mathrm{Bc}$ & $313 \pm 32$ & $0.4 \pm 0.1$ & $1.5 \pm 0.2$ & 55 & 110 & 104
\end{tabular}

ECAP passes. The decrease of the dislocation density at higher passes might be caused at least partly by the reduction of alloying element content inside the grains due to the formation of $\mathrm{Mg}_{17} \mathrm{Al}_{12}$ precipitates. From the fourth pass the dislocation density was found unchanged within the experimental error, which can be attributed to the balance between multiplication and annihilation of dislocations. The crystallite size decreases due to 1 pass of ECAP, then it increases up to four passes and slightly decreases after eight passes to the value of $313 \mathrm{~nm}$. The grain size determined by the EBSD method differs from the crystallite size, as the latter is equivalent to the size of coherently scattering domains and corresponds to dislocations cells or subgrains in SPD-processed metallic materials. The decrease of the crystallite size and the increase of the fraction of low-angle grain boundaries between 4 and 8 ECAP passes suggest that the dislocations inside the grains were arranged into boundaries or walls.
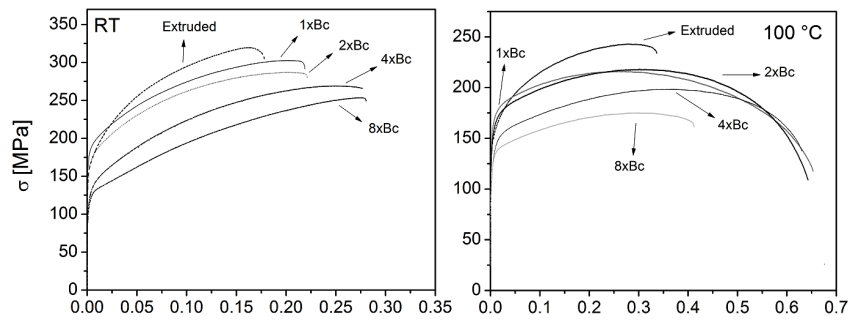

Fig. 3. True stress-true strain curves of extruded and EX-ECAPed samples obtained at room temperature and at $100{ }^{\circ} \mathrm{C}$.

Deformation curves obtained from tensile tests at both room temperature and $100^{\circ} \mathrm{C}$, for the particular specimen types are plotted in Fig. 3. The values of the yield strength $\left(\sigma_{02}\right)$ are summarized in the Table. As it is apparent from Fig. 4, the evolution of the room temperature yield strength with increase of number of ECAP passes is in accordance with the evolution of dislocation density. The $1 \times \mathrm{Bc}$ sample exhibits the highest value of yield strength of $178 \mathrm{MPa}$, which is about $15 \%$ higher

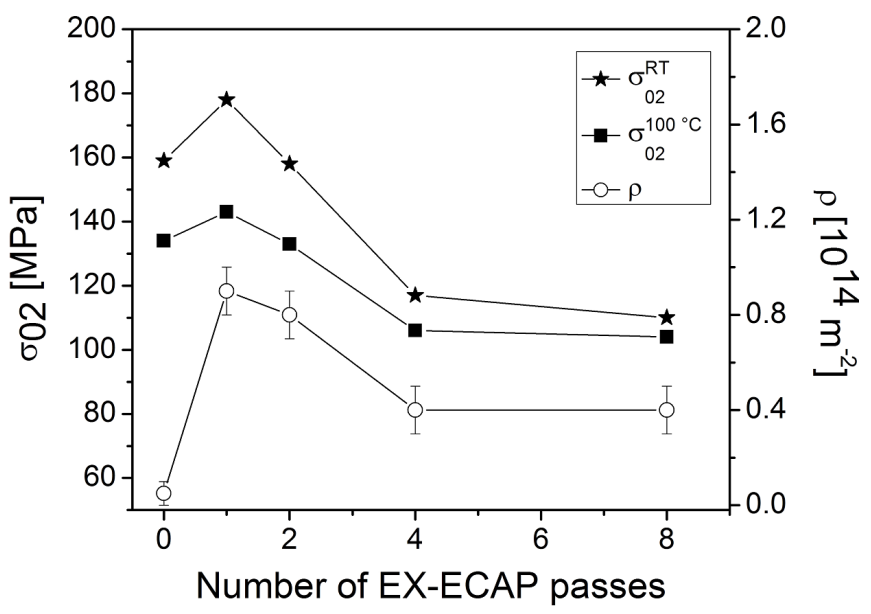

Fig. 4. Evolution of the dislocation density and the yield strength at room temperature and $100^{\circ} \mathrm{C}$ with increasing number of EX-ECAP passes.

in comparison with the as-extruded state. Further processing by ECAP led to the decrease in yield strength down to the value of $110 \mathrm{MPa}$ for $8 \times \mathrm{B}_{c}$ sample, despite the gradual fragmentation of the microstructure. It can be concluded that the strengthening caused by dislocations dominates over the Hall-Petch contribution of the grain size. The change of grain boundary strengthening during ECAP is small because there is only a slight decrease in grain size from the initial value of $3.8 \mu \mathrm{m}$ in the extruded state to $1.5 \mu \mathrm{m}$ after eight passes. Furthermore, the texture variation is probably responsible for unwanted softening of the material [13]. Tensile tests performed at $100{ }^{\circ} \mathrm{C}$ have shown only a slight $(5-30 \%)$ decrease in the yield strength while the ductility of all samples increased by a factor of about two. Good thermal stability of the yield strength was observed after four and eight passes at this temperature.

\section{Conclusions}

Experiments performed on an AX41 magnesium alloy showed that the increasing number of ECAP passes caused a gradual refinement of the initial, extruded microstructure. The grain size decreased from the initial value of $3.6 \mu \mathrm{m}$ in the extruded state to $1.5 \mu \mathrm{m}$ after eight passes and the bimodal character of the microstructure has changed to a unimodal one. Despite the refinement of the microstructure the yield strength decreases with increasing number of ECAP passes, which can be explained by the decrease of the dislocation density. Nevertheless, the $1 \times \mathrm{B}_{c}$ sample exhibits about $15 \%$ higher yield strength in comparison with the as-extruded state. The $4 \times \mathrm{B}_{c}$ and $8 \times \mathrm{B}_{c}$ samples exhibit very good thermal stability at $100^{\circ} \mathrm{C}$. The yield strength is similar to that at room temperature. In addition, the ductility increases by a factor of about two. 


\section{Acknowledgments}

This work was financially supported by Czech Science Foundation GACR under the grant P107/13/13616S and student foundation SVV 2014-265303. One of the authors J.G. acknowledges financial support by the Hungarian Scientific Research Fund, OTKA, grant No. K-109021.

\section{References}

[1] V.M. Segal, Mater. Sci. Eng. A 197, 157 (1995).

[2] D.H. Shin, B.Ch. Kim, Y. Kim, K. Park, Acta Mater. 48, 2247 (2000).

[3] Ch. Xu, K. Xia, T.G. Langdon, Mater. Sci. Eng. A 527, 205 (2009).

[4] L. Balogh, R.B. Figueiredo, T. Ungar, T.G. Langdon, Mater. Sci. Eng. A 528, 533 (2010).

[5] K. Máthis, J. Gubicza, N.H. Nam, J. Alloys Comp. 394, 194 (2005).

[6] C.W. Chung, R.G. Ding, Y.L. Chiu, W. Gao, J. Phys. Conf. Series 241, 012101 (2010).

[7] R.G. Ding, C.W. Chun, Y.L. Chiu, J. Phys. Conf. Series 241, 012105 (2010).
[8] R. Ninomiya, T. Ojiro, K. Kuba, Acta Metall. 43, 669 (1995).

[9] M.O. Pekguleryuz, A. Luo, Creep Resistant Magnesium Alloys for Die Casting, PCT (Patent Cooperative Treaty) application No. PST/CA96/00091, August 22 (1996).

[10] M.O. Pekguleryuz, J. Renaud, in: Magnesium Technology 2000 , Eds. H.I. Kaplan, J.N. Hryn, B.B. Clow, Wiley, USA 2000, p. 279.

[11] G. Ribárik, J. Gubicza, T. Ungár, Mater. Sci. Eng. A 387-389, 343 (2004).

[12] L. Balogh, G. Ribárik, T. Ungár, J. Appl. Phys. 100, 023512 (2006).

[13] T. Krajňák, K. Máthis, M. Janeček, J. Gubicza, IOP Conf. Ser. Mater. Sci. Eng. 63, 012058 (2014).

[14] Magnesium Alloys and Their Applications, Eds. M.O. Pekguleryuz, A.A. Kaya, K.U. Kainer, WileyVCH, Germany 2003.

[15] S. Biswas, B. Beausir, L.S. Tóth, S. Suwas, Acta Mater. 61, 5263 (2013).

[16] R.B. Figueiredo, T.G. Langdon, J. Mater. Sci. 44, 4758 (2009) 